\title{
Awareness, Perception And Practice Of Female Genital Mutilation Among Expectant Mothers In Jos University Teaching Hospital Jos, North-Central Nigeria
}

\author{
"Dattijo L M MBBS, Nyango D D FWACS, Osagie O E FWACS \\ Department of Obstetrics \& Gynaecology, Jos University Teaching Hospital, Jos, Nigeria
}

\begin{abstract}
Background: WHO estimates that some 130 million women worldwide are affected, and every year another 2 million girls and young women are at risk of undergoing the practice of FGM. Although Nigeria has a prevalence of $19 \%$ in 2003,a reduction from 25\% prevalence of 1999 national survey, it still has high absolute number of cases with wide regional variation. The awareness and perception of expectant mothers may give an insight as to what awaits their unborn daughters and have a bearing on the future of the practice.
\end{abstract}

Methodology: Semi-structured questionnaires were administered to 260 expectant mothers at the antenatal clinic of Jos University Teaching Hospital between $1^{\text {st }}$ and $31^{\text {st }}$ July 2007.

Results: Majority of the respondents (94.6\%) were aware of FGM. Mass media was the main source of information. Majority (83.8\%) wanted the practice to be discontinued, $31.3 \%$ reported having had FGM, most done by traditional healers. About $14.6 \%$ have a plan to circumcise their daughters citing tradition, marriage prospects, and faithfulness to husband as their reasons. Only 16.2\% wanted the practice to continue.

Conclusion: There is high level of awareness of the FGM among respondents who also have negative attitude to the practice, even as the practice is still prevalent. More health education is needed to illustrate the dangers of the practice in order to safeguard the health of the girl-child. *Abstract was presented at Sexual Violence Research Institute Forum(SVRI Forum 2009) in South Africa.

\section{Date Accepted for Publication: $18^{\text {th }}$ July 2010 \\ NigerJMed 2010:311 - 315 \\ Copyright@2010 Nigerian Journal of Medicine}

\section{Introduction}

World Health Organization (WHO) and the United Nations Population Fund (UNFPA) define female genital mutilation (FGM) as "the partial or total removal of the female external genitalia or other injury to the female genital organs for cultural or other non-therapeutic reasons" ${ }^{1-3}$.WHO estimates that some 130 million women worldwide are affected, and every year another 2 million girls and young women are at risk of undergoing the practice. There is no definitive evidence on the origin of the practice, although the tradition is believed to have originated some 2,000 years ago in southern Egypt or northern Sudan ${ }^{3,4}$.

FGM has health risks, most notably for women who have undergone more extreme forms of the procedure. Immediate potential side effects include severe pain, haemorrhage, injury to the adjacent tissues and organs, shock, infection, urinary retention, and tetanus. Some of these short-term side effects can be fatal $5^{5}$. Long-term effects may include cysts and abscesses, urinary incontinence, psychological and sexual problems, and difficulty with childbirth.

Tradition, custom, and religion all contribute to FGM, and it is mostly women who carry out and defend the practice ${ }^{3}$. With the onslaught of alien cultures and attacks by critics, some communities have aggressively sought to preserve FGM in the name of tradition, as a rite of passage into womanhood. One of the main reasons FGM is performed is to preserve girls' virginity for marriage, which carries a great deal of financial value and respect in FGM- practicing communities ${ }^{6,7 \text { and } 8}$.

Nigeria has the highest absolute number of cases of FGM due to its large population. It accounts for about one-quarter of the estimated 100-130 million circumcised women worldwide ${ }^{5,14}$. The 2008 National Demographic Health Survey (NDHS) revealed a national prevalence of $30 \%$. There is a wide regional variation with Southwest and southeast were 53.4\% and $52.8 \%$ respectively ${ }^{2,9,10}$. The Northeast has the lowest rate of $2.7 \%$, northwest has $19.6 \%$ while North central has $11.4 \%$. The practice of FGM is therefore found in most Nigerian communities. In the Survey, $62 \%$ of women favoured an end to the practice, with wide regional variation. The North central figure was $75 \%$.

The prevalence and perception of FGM of expectant mothers in our set up may give an insight as to what awaits their unborn daughters. The objective of this study was to determine the prevalence and perception of this practice among pregnant mothers in Jos, North central Nigeria, and region with a variety of ethnic 
groups. This would enable the design of interventions to eradicate this practice.

\section{Methodology}

\section{Study Setting}

Jos University Teaching Hospital is a 530 bed hospital, located in Jos North-central Nigeria. It receives patients from within Plateau, Benue, Nassarawa, Bauchi and Kaduna states. A multitude of ethnic groups inhabit the hospitals catchment area. Women attending antenatal clinic in the Hospital form the study population.

\section{Study Design}

A cross sectional study, a sample size of 236 pregnant women was calculated using the statistical formula for sample size determination ( $n=z 2 p q / d 2)$, where $n$ is sample size, $z$ is the standard normal deviate $(1.98) p$ is prevalence $(0.19), q$ is $1-p(0.81)$, d is error margin (0.05). However 300 pregnant women were recruited but 260 agreed to participate. A one in three systematic random sampling of all pregnant women attending antenatal care over a month period were studied ( $1^{\text {st }}-31^{\text {st }}$ July 2007$), 260$. A structured interviewer-administered questionnaire was used to collect information on sociodemographic characteristics, awareness, perception and practice of FGM.

\section{Analysis}

Results were analysed using Epi Info statistical software (version 3.3.2 CDC Atlanta). Descriptive statistics were used to describe the qualitative and quantitative variables. Chi square test was used to test for significance of associations. A p-value of less than 0.05 was considered significant.

\section{Results}

Majority of the respondents were in the age range of 20 30 years. The mean age was 27.5 years, median was 27. The youngest was 17 years while the oldest was 40 years. The major ethnic groups constituted $48.8 \%$ of the respondents-Hausa (19.6\%) Igbo (15.4\%), Yoruba(13.8\%).Others include Berom(8.8\%), Ngas (5.4\%), Mughavul (5.8), Edo(5\%), Tarok(3.8\%), and Tiv (3.5\%), table 1. About $59 \%$ of the respondents were Christians while $41 \%$ were Muslims. Majority of them were married (91.9\%).Housewives, traders and civil servants formed the bulk of the respondents. Parental education status revealed $35 \%$ had no formal education, $36.9 \%$ had only primary education, with only $11.5 \%$ having tertiary education. The respondents' educational status showed $46 \%$ had secondary level, $42 \%$ had tertiary with only2.3\% having no formal education.

Majority of the respondents have heard of FGM (94.6\%) while $5.4 \%$ have not. Based on the scores obtained by them, $70 \%$ have good knowledge of FGM while $30 \%$ have poor knowledge. The mass media (radio, television, newspapers) was the main source of information $(31.5 \%)$, followed by parents (24.3\%), Health workers(15\%).

Of the respondents that are aware of FGM, majority $(83.8 \%)$ wanted the practice to be discontinued while $16.2 \%$ wanted it to continue. About $14.6 \%$ of them have a plan to circumcise their daughters. Those against the continuation of the practice cited complications like HIV transmission, pain, infections and bad culture as their main reasons. While those that favour its continuation cited tradition, marriage prospects and faithfulness to husband, as their main reasons.

Prevalence of FGM among the respondents was $31.3 \%$, most of these women had clitoridectomy while the remaining was undetermined. About 35\% reported knowing someone who had FGM. Most of the procedures were done by Berber/traditional birth attendant $(50.6 \%)$, Heath workers did $8.2 \%$ while the remaining (41.2\%) was undetermined. Prevalence of FGM was highest among Igbos, Yoruba and Edo ethnic groups.

\section{Table I.Sociodemographic Characteristics of expectant mothers in JUTH 2007}

Characteristic

No

(\%)

$\begin{array}{lcc}\text { Age } & & \\ <20 & 21 & 8.1 \\ 21-25 & 75 & 28.8 \\ 26-30 & 100 & 38.5 \\ 31-35 & 57 & 21.9 \\ >35 & 7 & 2.7\end{array}$




\begin{tabular}{|c|c|c|}
\hline \multicolumn{3}{|l|}{ Ethnic group } \\
\hline Hausa & 51 & 19.6 \\
\hline Igbo & 40 & 15.4 \\
\hline Yoruba & 36 & 13.8 \\
\hline Berom & 23 & 8.8 \\
\hline Mughavul & 15 & 5.8 \\
\hline Ngas & 14 & 5.4 \\
\hline Edo (SM) & 13 & 5.0 \\
\hline Tarok & 10 & 3.8 \\
\hline Idoma & 9 & 3.5 \\
\hline Tiv & 9 & 3.5 \\
\hline Others (NM)ף & 40 & 15.4 \\
\hline \multicolumn{3}{|l|}{ Marital Status } \\
\hline Single & 9 & 3.5 \\
\hline Married & 251 & 96.5 \\
\hline \multicolumn{3}{|l|}{ Religion } \\
\hline Christian & 153 & 58.8 \\
\hline Muslim & 107 & 41.2 \\
\hline \multicolumn{3}{|l|}{ Education } \\
\hline None & 6 & 2.3 \\
\hline Primary & 24 & 9.2 \\
\hline Secondary & 120 & 46.2 \\
\hline Tertiary & 110 & 42.3 \\
\hline \multicolumn{3}{|c|}{ Parental Education } \\
\hline None & 92 & 35.4 \\
\hline Primary & 96 & 36.9 \\
\hline Secondary & 42 & 16.2 \\
\hline Tertiary & 30 & 11.5 \\
\hline
\end{tabular}

Table 2.Awareness of Female Genital Mutilation among 260 pregnant women in JUTH

\begin{tabular}{lrc} 
Variable & No & $\%$ \\
\hline Awareness of types & & \\
Clitoridectomy & 82 & 34.2 \\
Excision & 8 & 3.2 \\
Infibulations & 0 & 0 \\
Dont know & 163 & 63.9
\end{tabular}

\section{Source of information}

$\begin{array}{ll}\text { Parents } & 60\end{array}$

24.3

$\begin{array}{ll}\text { Relatives } & 12\end{array}$

Health workers 37

31.5

$\begin{array}{ll}\text { Combination } & 60\end{array}$

Mass media $\quad 78$

Awareness of complications

HIV transmission 213

86.3

Hepatitis

Pain

Wound Infection

Sexual dissatisfaction

Difficult delivery

Dont know

Others

Age of circumcision

$<1$ year

$1-5$ yeas

$>$ 5years

Practitioners who did the operation

TBA/barbers 43

50.6

Health worker

Traditional healer

Dont know

multiple responses

\section{Discussion}

The principal findings in this study are the high level of awareness of FGM (94.6\%) and strong negative attitude towards the practice $(83.8 \%)$ among the respondents. The study population is the mother of the next generation of girl-child and members of the reproductive age group. Majority are young with about $75.4 \%$ of them at least $30 y e a r s$ and below. This is similar to population studied in Kano and that of National Demographic Health Survey (NDHS) but different to the population studied in Lagos where over $60 \%$ of them were above 30 years ${ }^{2,10,11}$. Christians constituted $58 \%$ of the respondents while the rest were Muslims. About $89 \%$ had at least secondary education or higher. This high level of education may be due to selection bias associated with seeking tertiary health care. In contrast, the parental education status revealed over $72 \%$ of them had none or primary education only. 
The high level of awareness of FGM in this study is similar to that of Kano study $(90 \%)^{10}$. And higher than that reported by $\mathrm{NDHS}^{2}$. This could be attributed to the attention the practice has received from mass media and the areas studied. This is shown by the fact that mass media was the major source of information for over $30 \%$ of the respondent in the study.

While awareness of the practice was high, that of types was low. Clitoridectomy was known by only $33.2 \%$ with majority $66 \%$ not aware of the types of FGM. This finding was noted in the Kano study and also the NDHS where Clitoridectomy was the most common type of circumcision reported ${ }^{2}$. There were wide differences in awareness of the types among the various ethnic groups. While $58.3 \%, 67.5 \%$, of Yoruba and Igbo respondents respectively were aware of Clitoridectomy only $4.5 \%$ of Berom respondents were aware of it. This underscores the impact of culture on the practice. While among the two major ethnic groups is common, it is not so in the latter group.

Awareness of complications that could result from FGM was high. Leading the pack was HIV transmission (87.3\%),pain (80.6\%), sexual dissatisfaction (62.9\%) but hepatitis transmission (27.5\%). The pre-eminent role of HIV could have been due to the numerous campaigns on the disease rather than its association with FGM, These findings are similar to other studies from Kano and Akwa Ibom $^{9,10}$.

As to the continuation of the practice, only $15.8 \%$ of the respondents were in favour of it. This is similar to that of Kano (16.2\%) Northwest Nigeria, ${ }^{9,10,1}$, however is lower than that reported from Ibadan (67\%) and Lagos (37.6\%) in Southwest Nigeria. It is also lower than that obtained in Sudan $(79 \%)$, Egypt $(82 \%)$ and Eritrea $(60 \%)^{4,5,7,8}$.This clearly demonstrated the effect of cultural and geographical factors on the practice. The southwest region has high prevalence of the practice hence the higher percentage of those in favour of continuation compared to north-central region.

Of the respondents who wanted the practice to continue, $45.8 \%$ cited good culture/tradition ,marriage prospects( $14.3 \%)$ and chastity $(31.4 \%$ ) as their main reasons for the continuation. This further reinforces the role of culture and tradition in the practice of FGM reported in several studies worldwide ${ }^{4,5,7,8,12,13}$. The main reasons against its continuation among the respondents were Bad culture/tradition (45.8\%)Medical complications $(31.8 \%)$. This is the same order as reasons in the NDHS but the reverse of the findings in Kano ${ }^{2,9,10}$ where complications was the commonest reason. This further lends credence to the different perception of the practice among the ethnic groups that were captured in the study. Further subgroup analysis revealed that ethnic group strongly influenced the attitude of the respondents $(p<0.001)$. While only $2.4 \%$ of Hausa respondents wanted the practice to continue, $69.4 \%$ wanted it among Yoruba respondents with none among minority ethnic groups of the Plateau. Religion of the respondents has no association with the practice in this study $(p=0.254)$

The prevalence of FGM in the study was $31.3 \%$. This is lower than that reported from Eritrea $(90 \%)$, Somalia(98\%),Egypt (89\%) ,Port-Harcourt, Nigeria(53.2\%) but similar to that of Ghana(30\%), higher than Kano(23.3\%),north western Nigeria ${ }^{2,3,7,8,9,10,11,12}$. This is also higher than the NDHS figures of $10 \%$ for the north central zone. This could be explained by the cosmopolitan nature of the study area. Subgroup analysis further revealed $72 \%$ of Igbo respondents reported been circumcised while none among minority ethnic groups of the plateau. This further reinforces the influence of culture associated with the ethnic groups. Most of those circumcised (66\%) do not know the type that was done, $33.2 \%$ had Clitoridectomy and $0.8 \%$ reported excision. There was no report of infibulations. This largely conformed to finding of NDHS which put Clitoridectomy as the most common type done in Nigeria. This is a sharp contrast with reports from the horn of Africa where infibulation in $82 \%$ of cases in Sudan ${ }^{4,5}$.

Most of those circumcised had it in the first year of life (44.6\%) while $41 \%$ had it between one and five years of life. This did not differ from the finding of NDHS which reported that most of circumcisions were performed within the first year of life. Also in Lagos $70 \%$ of circumcision were done during infancy ${ }^{2,11}$.

Traditional birth attendants (TBA)/traditional practitioner performed most of the procedures $50.6 \%$ while $8.2 \%$ was by health workers. Medicalisation of FGM has been noted in some countries like Egypt $(61 \%)$ and Sudan (34\%) and Nigeria (9\%) 1, 3, 4,6,14. The World Health Organisation (WHO) frowns at it. While it may improve the condition under which FGM is performed, it violates principles of professional health ethics and does not address violation of women's right. In Nigeria the practice is largely in the domain of TBA/traditional healers as shown by NDHS where $64 \%$ were done by them ${ }^{9}$. 
As to the future of this practice, $14.6 \%$ of the respondents intended to circumcise their daughters. This is similar to figures reported from Kano (13.8\%) but lower than 22\% reported in the NDHS ${ }^{2}$. Both areas are in zones with low prevalence of FGM in the country ${ }^{2}{ }^{9}$. While educated mothers are less likely to have the intention to circumcise their daughters $(p<0.001)$, the influence of culture may

\section{References}

1. WHO study group on female genital mutilation and obstetric outcome. Female genital mutilation and obstetric outcome: WHO collaborative prospective study in six African countries. Lancet 2006; 367:18351841.

2. National Population Commission (NPC) [Nigeria] and ICF Macro. 2009. Nigeria Demographic and Health Survey 2008. Abuja, Nigeria: National Population Commission and ICF Macro.

3. Toubia N. Female Genital Mutilation: An Overview. Geneva: World Health Organization (WHO); 1998.

4. Toubia N, Sharief E. Female genital mutilation: Have we made progress? Int J Gynecol and Obstet 2003; 82:251261.

5. United Nations Population Fund (UNFPA) website. Frequently asked questions about female genital cutting. Available at: www.unfpa.org/ gender/faq_FGM.htm. Accessed September 3,2007.

6. World Bank. Female Genital Mutilation/Cutting in Somalia. Washington, DC: World Bank; 2004.

7. National Statistics and Evaluation Office (NSEO) [Eritrea] and ORC Macro. Eritrea Demographic and Health Survey 2002. Calverton, MD: National Statistics and Evaluation Office and ORC Macro; 2003. explain the high prevalence of the practice among ethnic groups of southern Nigeria who are comparatively more educated.

Though there is high level of awareness of FGM among the respondents who also have negative attitude to it, the practice is still with us and further intensification of campaigns is needed to end this practice.

8. Muteshi J, Sass J. Female Genital Mutilation in Africa:AnAnalysis of CurrentAbandonment Approaches. Nairobi: PATH; 2005.

9. Ugboma HAA,Akani CI,Babatunde S. Prevalence and medicalization of Female Genital Mutilation. Niger J Med 2004;13(3):250-253.

10. Abubakar I S,llyasu Z, Kabir M, Uzoho C C, Abdulkadir MB. Knowledge, Attitude and Practice of Female genital cutting among antenatal patients in Aminu Kano Teaching Hospital, Kano.

11. Odunjinrin OMT,Akintoye CO,Oyediran MA. A study on female genital mutilation in Nigeria. W Afr J Med 1989;8(3):183-192.

12. Adongo $P, A$ keongo $P$, Binka $F$, Mbacke C.Sociocultural factors that influence the practice in Kassena-Nankana District, Ghana.Afr J Reprod Health 1998;2(2):21-24.

13. Toubia N. Female circumcision as a public health issue. N Engl J Med 1994; 331:71216.

14. UNDP/UNFPA/WHO/World Bank. Female Genital Mutilation-New Knowledge spurs optimism. Progress in Sexual and Reproductive Health Research 2006; 72. 